\title{
Viewpoint: Stochastic research, management implications, and the Journal of Range Management
}

\author{
DAVID L. SCARNECCHIA
}

Author is Associate Professor, Department of Natural Resource Sciences, Washington State University, Pullman, Wash., and Book Review Editor, Journal of Range Management.

\begin{abstract}
This viewpoint paper examines criteria for preparing and evaluating manuscripts that involve stochastic approaches. Increasing use of stochastic mathematics to address inherent uncertainty in natural systems has meant increasing challenges to write and evaluate the manuscripts reporting such research. The paper provides a set of criteria directed at aiding authors, referees and associate editors in writing and evaluating this research. The paper asserts that for research papers to be acceptable to a management science journal such as the Journal of Range Management, they should at least be mathematically appropriate, functionally valid, pragmatically justified, technically comprehensible, and generally readable. It then examines the relationship of the concept of synthesis to the management implications sections of journal articles. The paper advocates increased attention to the concept of synthesis in making papers that report stochastic research in particular, and technical research in general, more understandable to readers, and more useful in range management science.
\end{abstract}

Key Words: synthesis, editorial philosophy, probability, uncertainty, range management science, Society for Range Management

"The theory of probability is at bottom nothing but common sense reduced to calculus." -French mathematician Pierre Simon de Laplace (1749-1827).

In recent years, probabilistic mathematics has been applied with increasing frequency to problems of rangelands. Such stochastic applications often seem more effective than deterministic descriptions in predicting or explaining events related to plant community (state) transitions, rangeland health, weed invasions, weather, or other events that are describable using probability distributions. Evaluating papers that present such approaches often introduce referees, associate editors and editors of management science journals like the Journal of Range Management to specialized mathematics more common to mathematics journals than to those involving rangelands. This paper examines the general criteria for writing and evaluating papers involving stochastic research. Many of the observations offered are relevant to research papers in general.

Objectives of this viewpoint paper are to (1) assist in both effective presentation and editorial evaluation of papers with stochastic elements, (2) examine the importance of scientific synthe-

\footnotetext{
Manuscript accepted 16 Mar. 03.
}

\section{Resumen}

Este artículo de opinión examina criterios para preparar y evaluar manuscritos que involucran métodos estocásticos. El uso creciente de matemáticas estocásticas para abordar la incertidumbre inherente en un sistema natural ha significado aumentar los retos de escribir y evaluar manuscritos reportando tal investigación. El artículo provee un grupo de criterios dirigidos a auxiliar a los autores, revisores y editores asociados en escribir y evaluar esta investigación. El articulo afirma que para que los artículos de investigación sean aceptables para un journal de ciencias de manejo tal como el Journal de Manejo de Pastizales, ellos, al menos, deben ser matemáticamente apropiados, funcionalmente validos, justificados pragmáticamente, técnicamente comprensibles y generalmente leíbles. Examina la relación del concepto síntesis a las secciones de implicaciones de manejo de los artículos del journal. Este artículo aboga por una mayor atención al concepto de síntesis para hacer los artículos, que reportan investigación estocástica en particular e investigación técnica en general, más entendible para los lectores y más útiles en la ciencia de manejo de pastizales.

sis, and its relevance to stochastic research and to the management implications sections of journal articles reporting stochastic research and other research, (3) encourage greater attention in general to the process of synthesis in interpreting research in range management science, and (3) improve the readability of the Journal of Range Management.

\section{Evaluation of Manuscripts with Stochastic Elements}

Authors should explain the reasons for use of probabilistic or stochastic elements in their models, and in papers describing their research. Most basic to this explanation is the appropriateness of the stochastic application to the process involved. The uncertainty characteristic of these processes should involve randomness and be describable by a probability distribution. For example, weather may be described stochastically in a model as an input, as an internal feature of a model, or as an output. Similarly, in a model of plant community succession, community changes as model outputs may appropriately be described stochastically.

Other events are appropriate or inappropriate for stochastic treatment depending on the degree of deterministic control of those events. The distribution of free-ranging cattle on rangeland can appropriately be described by stochastic output. But, for example, as an output, the stocking of cattle in the different pastures within an intensive grazing system is better modeled deterministically because the manager ultimately determines which 
pasture is grazed. In such a case, the events that lead up to the decision may be described stochastically, but the decision is deterministic. The researcher and author should make the distinction between the analytical process, that may be described stochastically, and the actual decision, that in the absence of tumbling dice, maybe deterministic.

Even if analytically appropriate, a stochastic approach will have value only if it has, in a systems sense, validity. Probability distributions are sometimes attributed inordinate credibility because of their inherent acknowledgement of uncertainty. Still, probability distributions are at best only as valid as the data or theory that produce them, even though inadequacies in the theories or data that produced them are sometimes obscured by the complexity of probabilistic mathematics. In any case, just as in any other modeling, immediate internal verification is not a substitute for protracted external validation, and validation should involve more than solutions to trivial cases. Also, error can be propagated just as readily in subsequent applications of stochastic approaches as it can in applications of deterministic ones. A researcher and author can address validation in various ways depending largely on the rigor required to achieve objectives. But however an author establishes it, the functional validity of a stochastic approach is critical to the ultimate value of the approach.

Once appropriateness and validity are considered, stochastic approaches need to be pragmatically justified by authors. If a stochastic approach is, as discussed above, appropriate, its superior compatibility should inherently make it technically superior. How much superior, and is the superiority worth the added complexity become the relevant questions. If stochastic approaches are more complex, authors of research involving them should, at minimum, qualitatively justify their greater complexity. Simply asserting that uncertainty exists and that the processes or events modeled involve uncertainty is not necessarily adequate justification for highly complex stochastic approaches in an objective-oriented management science. Ideally, researchers should follow as formal and quantitative an approach as possible in establishing validation criteria for their stochastic analyses, just as an experimental scientist should, where appropriate, establish justifiable criteria for testing hypotheses or evaluating confidence intervals, or any modeler should establish validation criteria for success of a modeling effort. This quantitative evaluation may involve formal assessment of the marginal benefit of an approach against the marginal cost of its increased complexity in some analytical (but not necessarily economic) currency, or may be a less formal model of relevant trade-offs. In any case, such marginality evaluation should be an essential element of pragmatic justification in a journal of management science like the Journal of Range Management.

\section{Comprehensibility and Readability}

The things that pass for knowledge I can't understand...

-lyric from Reeling in the Years by Steely Dan

Stochastic papers are challenging to review and referee partly because of their low comprehensibility. Most readers with orientations toward management science or actual management relate poorly to stochastic approaches, especially if they are not well explained. When the main research methodology in a paper involves stochastic mathematics, the author should explain the function, if not the intricacies, of that methodology in terms understandable to a non-specialist scientist. Meaningful evaluation of the utility of an analytical methodology without comprehension of at least its basic function is unlikely.

Evaluation of utility is especially difficult when the stochastic elements of a research paper are in the output, and the stochastic outputs are inadequately linked to (i.e., translated into) verbal management science. Verbal explanations rich in jargon rarely enlighten. Beyond being technically comprehensible, a paper will be readable only if jargon is minimized, ideally with little compromise of precision. Authors of papers, including ones involving stochastic elements, need to give special attention to translation of their results, discussions and interpretations into comprehensible, readable management science. And management science journals that provide tools and information for nonspecialist managers should have higher standards of comprehensibility and readability than journals of experimental science that may publish research lacking obvious or immediate applications.

\section{Synthesis in Relation to Management Implications and Management Science}

In view of the preceding discussions of comprehensibility and readability, the quotation by Laplace that opened this paper should be considered. Because mathematics is a language of abstraction, and abstraction involves simplification and generalization, calculus, as a form of mathematics, is an abstraction involving simplification and generalization. Interpreted literally, Laplace's statement implies that if probability is common sense reduced (in a reductionist sense) to mathematics, then mathematics requires synthesis into common sense, i.e., into readily comprehensible knowledge. So translation into management implications is not reductionist simplification, but instead should be treated as synthesis of a high order-synthesis into precise management science made useful in part by being made understandable. Data require synthesis into information, a concept long understood in systems science. Authors sometimes minimize this synthesis in reporting results of research.

The evidence of lack of attention to this final step in synthesis in research can be found in the management implications sections at the end of many journal articles reporting stochastic research, or other analytical research, including experimental research, in the Journal of Range Management and other journals. Often these sections are abbreviated, and may seem hastily appended. They are sometimes sketchy and imprecise when compared to the detailed materials and methods and statistical results and discussion sections that they usually follow.

In fact, the inclusion of a section of a paper in the Journal of Range Management entitled management implications is arguably superfluous in that the management implications of a well-written paper in a management science journal should be obvious throughout its design and writing. Even if it has technical merit, research involving esoteric science and mathematics that is devoid of apparent management implications is not ideally suited to journals of management or management science. For a paper to be well designed for a journal of management science, management implications should permeate its design, i.e., its objectives, methodology, figures and tables, statistical analyses, and discussions. This recommendation is a broadened extension of several recommendations of Gould and Steiner (2002) regarding experimental research, among them "that the practical significance (as opposed to statistical significance) be considered more often." The verbal synthesis of management implications, i.e., the conversion of results into precise but understandable, readable lan- 
guage can be especially important in esoteric stochastic research. For any paper though, synthesis of an understandable, readable, verbal interpretation is critical to the readability of a paper, the contribution of the manuscript to the Journal of Range Management, and the value of the research to range management science.

Emphasis on synthesis in analysis and evaluation of stochastic research is consistent with recommendations made elsewhere (Scarnecchia 2003, 2004) about the importance of an expanded role of synthesis in the editorial philosophy of the Journal of Range Management. By emphasizing the importance of synthesis in analysis and communication in range management science, authors, editors, and referees can increase the probability that published papers, including those involving stochastic elements, will have greater technical merit, will be more understandable, and will be more applicable to realworld problems.

\section{Literature Cited}

Gould, W. R. and R. L. Steiner. 2002. Viewpoint: Improving range science through appropriate use of statistics. J. Range Manage. 55:526-529.

Scarnecchia, D. L. 2003. Viewpoint: Empowering diversity: Envisioning, designing and developing range management science. J. Range Manage. 56:558-569.

Scarnecchia, D. L. 2004. Viewpoint: Synthesis, range management science, and the Journal of Range Management. J. Range Manage. 57:117-120. 